\title{
Correction to: Relationship approach to crowdfunding: how creators and supporters interaction enhances projects' success
}

\author{
Kalanit Efrat ${ }^{1,2}$ (D) $\cdot$ Shaked Gilboa ${ }^{1} \cdot$ Arie Sherman $^{1}$ \\ Published online: 18 January 2020 \\ (C) Institute of Applied Informatics at University of Leipzig 2020
}

\section{Correction to: Electronic Markets} https://doi.org/10.1007/s12525-019-00391-6

The original version of this paper unfortunately contained error, Arie Sherman is inadvertently deleted in the authorgroup, which is now corrected.

Publisher's note Springer Nature remains neutral with regard to jurisdictional claims in published maps and institutional affiliations.

The online version of the original article can be found at https://doi.org/ 10.1007/s12525-019-00391-6

\footnotetext{
Kalanit Efrat

kalanite@ruppin.ac.il; kalanite@uia.no

Shaked Gilboa

shakedg@ruppin.ac.il

1 Ruppin Academic Center, 40250 Emek Hefer, Israel

2 University of Agder, 4604 Kristiansand, Norway
} 